
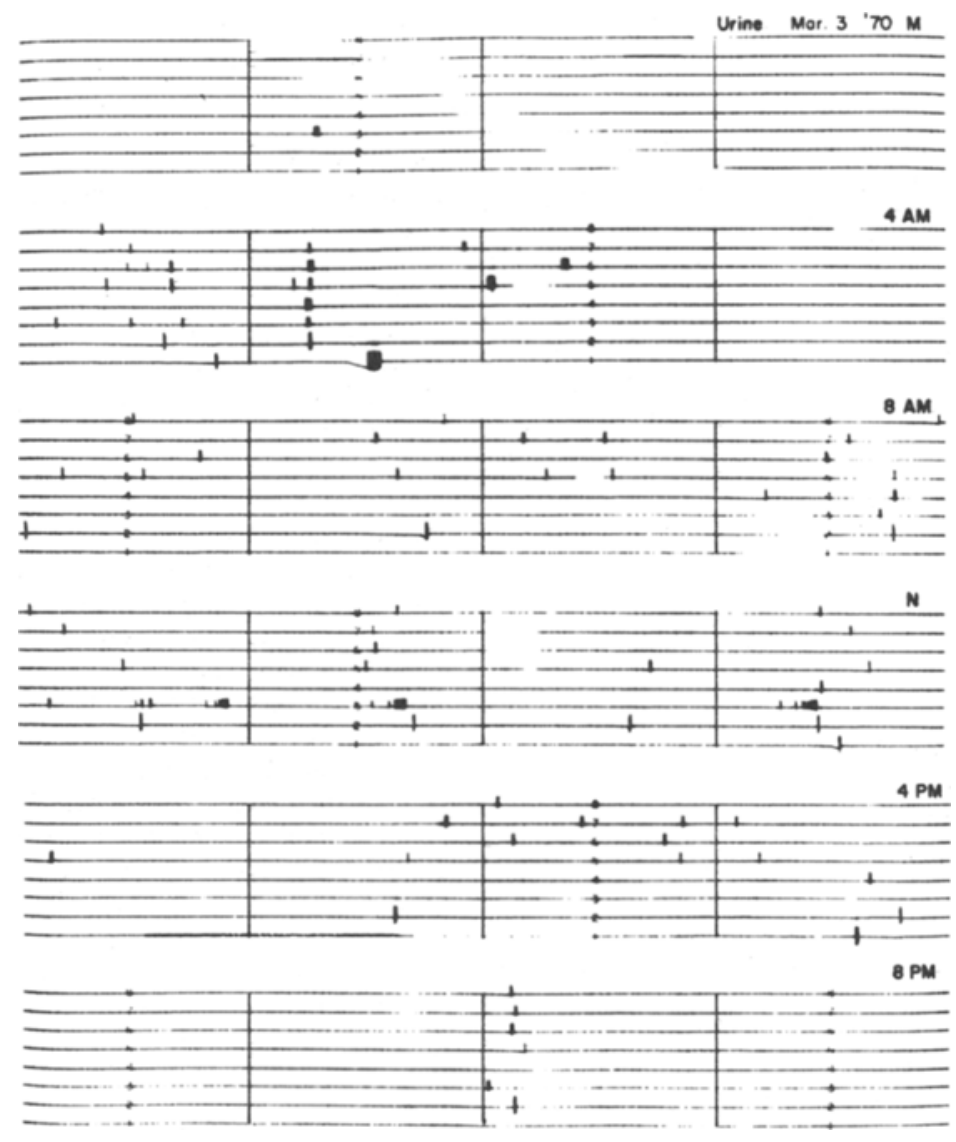

these patterns to time and amount of water intake, activity, and other measures, several interesting findings can be obtained from the single-day record in Fig. 3. Six of eight animals urinated within a few minutes of each other at 6:45 a.m. and again at approximately 9:50 p.m. While the time of urination is more variable at other times of the day, seven animals urinated within a $15-\mathrm{min}$ period at approximately $12: 30$ p.m. and six animals urinated within to the test room.
Fig. 3. A 24-h event record showing time of day of urination for eight rhesus monkeys. The record starts with midnight (M) in the upper right hand corner and reads from right to left in 4-h blocks.

interest. The frequency of urination is 4 , $12,12,6,20,11,15$, and 9 for Animals 1 through 8, respectively. Animal 1 urinated a large amount at 6:30 a.m., and then voided only three times thereafter. Animal 3 voided at $2: 45$ a.m., whereas no other animals voided in the middle of the night.

\section{REFERENCES}

DYKMAN, R. A.. CORSON, S. A., REESF. W. G., \& SEAGER, L. D. Inhibition of urine flow as a component of the conditional defense reaction. Psychosomatic Medicine, 1962. 24, 177.186.

IEELDMAHN, A. L, SMITH, W. K., \& LEVENTHAL, C. M. Diurnal patterns of micturation and drinking in rhesus monkeys. Annals of the New York Academy of Science, $1960,85,828-841$.

HOSHIZAKI, T., ADEY, W. R., MEEHAN, J. P. WALTER, D. O., BERKHAUT, J. I., and CAMPEAU, E. Central nervous, cardiovascular, and metabolic data of a Macaca nemestrina during a 30-day experiment. In F. H. Rohles (Ed.), Circadion thythms in nonhuman primates, Basel: S. Karger, 1969. Pp. 8-38.

JARVIK, M. E., \& CARLEY, J. L. A simple circuit for contact responses. Journal of the Experimental Analysis of Behavior, 1964, 7, 82.

NICHOLSON, J. D., \& WARWICK, I. S. A temperature and light sensitive electronic circuit. Joumal of Science Technology, 1969, $15,86-88$.

ROHLES, F, H., JR., \& OSBALDISTON, G. Social entrainment of biorhythms in thesus monkeys. In F. H. Rohles (Ed.), Circadian rythms in nonhuman primates. Basel: S. Karger, 1969. Pp. 39-51.

\section{NOTE}

1. This paper was supported by NIH Grant

Individual differences are also of

FR-00164 and HD 03915 .

\title{
An electroluminescent lamp device for critical flicker fusion and apparent motion
}

C. C. BROWN and D. KRAUSMAN, MARYLAND PSYCHIATRIC RESEARCH CENTER, Box 3235, Catonsville, Maryland 21228

$A$ circuit that uses electroluminescent lamps as light sources for the study of critical flicker fusion (CFF) and apparent motion phenomena is described. The technique involves the modulation of a $2 \cdot \mathrm{KHz}$ exciting current with a multivibrator-formed pulse adjustable over a suitable range of frequencies. Components are readily available from commercial sources.

Wide use of the perceptual test of critical flicker fusion (CFF) and apparent motion phenomena is limited by the expense and complexity of commercial circuitry. Most of this equipment uses xenon-filled crater lamps (RC 1130 B) which require high-power vacuum-tube driver circuits. A further disadvantage is that this type of light source produces an intense spot rather than a uniform field of illumination. 


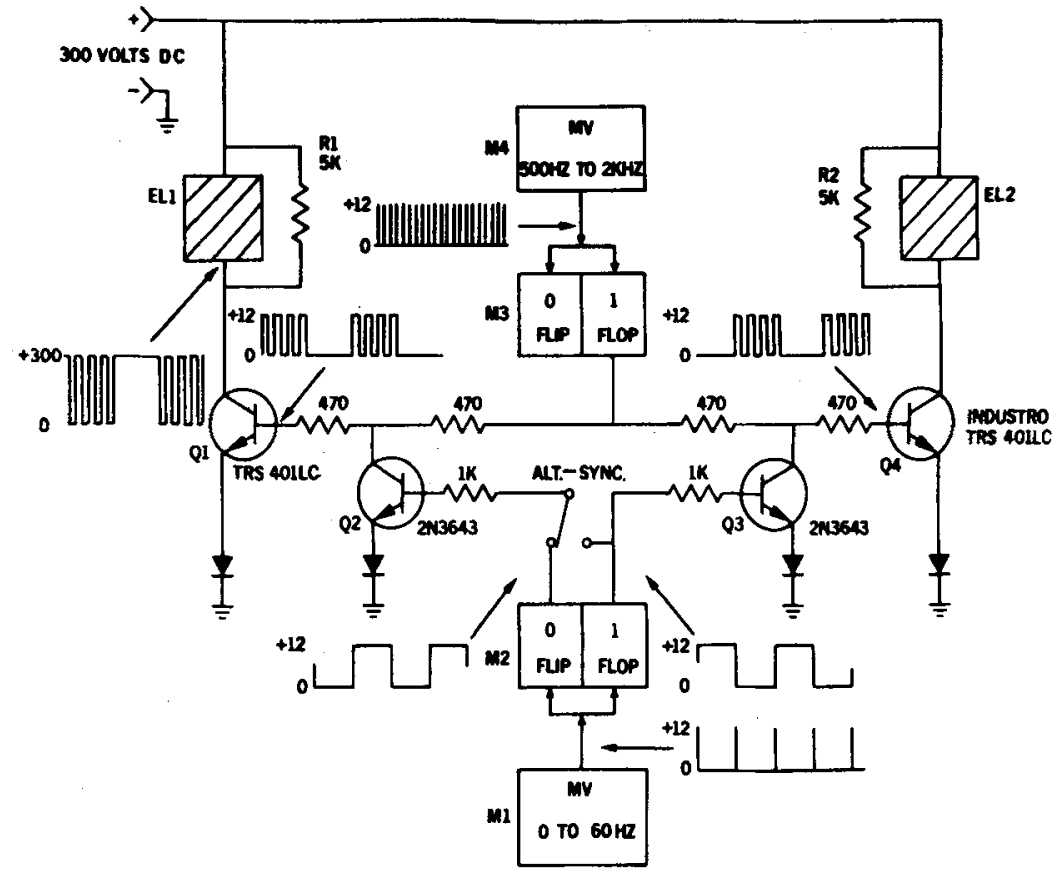

The circuit described here uses electroluminescent lamps (EL) in a manner first proposed by Montagu (1966). The transistorized circuitry provides for either synchronous or alternate illumination of two such EL sources so that the $E$ can produce either the CFF or apparent motion phenomena.

The EL lamp is made by embedding an electroluminescent phosphor in an insulating substance between two parallel conducting plates, one of which is optically transparent. When an alternating current is applied to these conductors, it causes the phosphor to glow much in the same manner as does the coating on the face of a cathode-ray tube. The color of the light produced is a function of both the composition of the phosphor and the frequency of the applied current. While EL lamps are available in sizes up to $12 \times 12$ in., and in several colors as well as "white," the inexpensive lamps used in this circuit produce a greenish-yellow glow and are sold in hardware stores as night lights.

Since dc current will not cause the phosphor to glow, the EL must be powered by a pulsed dc or ac source at a frequency above the flicker-fusion threshold of the dark-adapted eye. The light output vs excitation frequency curve of these lamps rises slowly with increasing frequency until saturation occurs, and ultimately a drop in light output takes place at still higher frequencies.

Since it was desirable to produce both maximum light output in the lamp and to avoid visible "beat" phenomena between the excitation frequency and the modulation frequency $(0$ to $60 \mathrm{~Hz})$, an excitation frequency of $2 \mathrm{KHz}$ was chosen. Because of the nonlinear relationship between applied voltage and brightness in the EL, sinusoidal modulation produces a distorted brightness-frequency output characteristic. Accordingly, square-wave dc pulsed modulation and excitation was used. The circuit diagram for this device is shown in Fig. 1. Operation is as follows:

Standard logic modules are used for M1, $\mathrm{M} 2, \mathrm{M} 3$, and M4. They produce a $+12 \cdot \mathrm{V}$ level in the "on" state and 0 level in the "off" state and are capable of delivering $30 \mathrm{~mA}$ of output current. The multivibrator M4 produces the excitation frequency that is used to drive $M 3$, the output of which modulates the bases of transistors Q1 and Q4. These two transistors are special high-voltage transistors that contain the ELs in their collector loads. Thus, with only the excitation signal applied to base of Q1 and Q4, both lamps would be "on" at an apparently steady level of brightness. $M 1$ is a free-running multivibrator variable from 0 to $60 \mathrm{~Hz}$ that drives $M 2$, a flip-flop
Fig. 1. Q1 and Q4 are inexpensive high-voltage transistors (Industro) requiring heat sinks, while $Q 2$ and $Q 3$ are low-voltage NPN silicon switching transistors. M1, M2, M3, and M4 are BRS Digibit modules Type MV-209 and FF-201. The modules have been modified from negative to positive logic by changing the applied voltage from the 0 and $-12 \mathrm{~V}$ required to +12 and $0 \mathrm{~V}$, respectively. All diodes are Type $1 \mathrm{N4005}, \mathrm{R} 1$ and $\mathrm{R} 2$ are 20.W resistors, all others are $1 / 2-W$. EL 1 and EL 2 are night lights, $2^{1 / 4} \times 1^{3 / 4}$ in., 1/10-W, $125-\mathrm{V}$, sold in "blister" packs.

providing base signals to transistors $Q 2$ and Q3. Thus, the frequency setting of $\mathrm{M} 1$ is the modulation frequency and causes the EL lamps to be switched on and off at that rate. The EL lamps may be switched alternately. as shown by the indicated switch position in the drawing, in which case Q2 and Q3 are alternately turned on by the opposing sides of M2. When the "alt-sync." switch is thrown to the "sync." position, both lamps are flashed synchronously at the frequency determined by $\mathrm{M} 1$.

The power supply for the lamps should be able to provide regulated $300 \cdot \mathrm{V}$ dc with a current capacity of $100 \mathrm{~mA}$ or greater. The resistors, $R 1$ and $R 2$, are paralleled across the EL lamps to provide a discharge path for the lamp during the "off" state. Modules (M1 through $M 4$ ) require a regulated $12-\mathrm{V}$ supply with the negative side connected to the negative of the $300-V$ excitation supply.

It is evident that when used in the apparent motion mode ( $50 \%$ duty cycle), one light is extinguished and is followed immediately by the illumination of the second. The circuit shown has operated in a virtually trouble-free fashion and has required a very minimum of construction, time, and material since commercial (BRS digi-bits) modules (modified from negative to positive logic) were used wherever possible. As suggested by Montagu, the EL lamps may be mounted at the ends of a binocular arrangement, thus permitting their use with a $\mathrm{S}$ in a normally lighted room.

\section{REFERENCE}

MONTAGU, J. D. The application of electro-luminescense and photic stimulation. EEG Clinical Neurophysiology, 1966, 21, 393-395. 